\title{
Robotic radical hysterectomy for early-stage cervical cancer: A systematic literature review
}

\author{
Gun Oh Chong ${ }^{1,2}$ \\ ${ }^{1}$ Department of Obstetrics and Gynecology, School of Medicine, Kyungpook National University, Daegu; ${ }^{2}$ Department of Obstetrics and Gynecolo- \\ gy, Kyungpook National University Chilgok Hospital, Daegu, Korea
}

Robotic technology has recently come into widespread use to overcome the limitations of laparoscopic radical hysterectomy in the treatment of early-stage cervical cancer. Most comparative studies showed that blood loss and hospital stays for patients undergoing minimally invasive surgery, including robotic procedures, were superior compared to open surgery. Moreover, the survival outcomes of robotic radical hysterectomy were not inferior to open radical hysterectomy. Unexpectedly, the Laparoscopic Approach to Cervical Cancer (LACC) trial, a randomized, open-label, noninferiority study that compared minimally invasive radical hysterectomy with open radical hysterectomy, revealed that minimally invasive surgery was associated with a higher risk of recurrence and death compared with open surgery. Strict guidelines for robotic radical hysterectomy for the treatment of early-stage cervical cancer should be established in accordance with objective Korean data. In addition, it is recommended that further studies should be performed on how to avoid the use of uterine manipulators and the dissemination of cancer cells by ensuring a more effective vaginal closure using a standardized approach.

Key Words: Cervical cancer; Radical hysterectomy; Robot

\section{INTRODUCTION}

Radical hysterectomy $(\mathrm{RH})$ is a well-established treatment modality of early-stage cervical cancer. $\mathrm{RH}$ is defined as the en bloc removal of the uterus and cervix with the surrounding parametrial tissue and upper vagina. Since the introduction of conventional laparoscopy, improvements in gynecologic surgery have been notable. However, laparoscopic RH (LRH) remains a rather unpopular choice among gynecologic oncologists because of the increased operative time and the steep learning curve required for competency [1]. Robotic technology has recently come into widespread use to overcome the limitations of laparoscopic surgery [2]. This is because robotic surgery provides more surgical options, such as nerve-sparing technique, due to its superior visualization (3-dimensional imaging of the operative field), mechanical improvement (seven degrees of instrument mobility inside the body) and stabilization/tremor filtration

- Received: September 9,2021 • Revised: September 20, 20201 •Accepted: September 20, 2021

- Correspondening author: Gun Oh Chong

Department of Obstetrics and Gynecology, Kyungpook National University Chilgok Hospital, 807 Hoguk-ro, Buk-gu, Daegu 41404, Korea

E-mail:gochong@knu.ac.kr

This is an Open Access article distributed under the terms of the Creative Commons Attribution Non-Commercial License (http://creativecommons.org/ licenses/by-nc/4.0) which permits unrestricted non-commercial use, distribution, and reproduction in any medium, provided the original work is properly cited. 
of the instrument within the surgical field [2].

Unexpectedly, the Laparoscopic Approach to Cervical Cancer (LACC) trial, a randomized, open-label, noninferiority study that compared minimally invasive $\mathrm{RH}$ with open $\mathrm{RH}(\mathrm{ORH})$, found that minimally invasive surgery (MIS) was associated with a higher risk of recurrence and death compared with open surgery. Female patients randomized to the minimally invasive surgery arm experienced an almost four times greater risk of recurrence and six times greater risk of death compared with female patients that were randomized to laparotomy [3]. In a statement released after the publication of the LACC trial, the Society of Gynecologic Oncology encouraged surgeons to discuss these data with patients undergoing surgery for cervical cancer [4], and the National Comprehensive Cancer Network cervical cancer guidelines were revised accordingly to define the open abdominal approach as the "standard and recommended approach to $\mathrm{RH}$ " [5].

Consequently, this study performed a systemic literature review to appraise and synthesize the available real-world evidence on robotic $\mathrm{RH}(\mathrm{RRH})$. Moreover, we compared the risk of recurrence and death between patients who underwent MIS vs. ORH for early-stage cervical cancer.

\section{CASE SERIES OF RRH}

After Marchal et al. [6] performed RRH in 2005, several case series of RRH were published (Table 1) [7-10]. In Korea, Kim et al. [7] for the first time reported 10 cases of $\mathrm{RRH}$ and concluded that RRH for selected patients with IB1 cervical cancer is feasible, promising and related with a low morbidity (Table 1).

\section{MIS (ROBOT AND LAPAROSCOPY) VS. OPEN}

Most initial comparative studies between MIS and ORH focused on the respective surgical outcomes [11-14]. Most comparative studies showed that blood loss and hospital stays for the MIS group were superior compared to the open group [11-17]. Furthermore, previous retrospective comparative studies revealed that the survival outcomes of MIS were comparable to the survival outcomes of open surgery [15-17]. In the LACC trial, however, MIS was associated with a lower range of disease-free survival (DFS; 3-year rate, 91.2\% vs. 97.1\%; hazard ration [HR], 3.74; 95\% confidence interval [Cl], 1.63-8.58) and overall survival (OS; 3-year rate, 93.8\% vs. 99.0\%; HR, 6.00; 95\% Cl, 1.7720.30) [3]. Following the LACC trial, several retrospective comparative studies reported on the survival outcomes of MIS and open surgery [18-20]. Cusimano et al. [18] showed that MIS was associated with increased rates of death ( $\mathrm{HR}$, 2.20; 95\% Cl, 1.15-4.19) and recurrence (HR, 1.97; 95\% $\mathrm{Cl}, 1.10-3.50)$ after adjusting for individual patients' factors and surgeon volume. Moreover, an international European cohort observation study (the SUCCOR study) demonstrated that the risk of recurrence for patients who underwent MIS was twice as high compared to the open surgery group (HR, 2.07; 95\% Cl, 1.35-3.15; $P=0.001)$. Similarly, the risk of death was 2.42 -times higher than in the open surgery group (HR, 2.45; 95\% Cl, 1.30-4.60, $P=0.005)$ [19]. Finally, Brandt et al. [20] reported that MIS $\mathrm{RH}$ did not confer worse oncologic outcomes in a singlecenter retrospective study (Table 2).

Table 1. Case series of robotic radical hysterectomy

\begin{tabular}{|c|c|c|c|c|c|c|c|c|c|c|c|}
\hline Year & Nation & Number & Design & Stage & $\begin{array}{c}\text { Operative } \\
\text { time } \\
\text { (minutes) }\end{array}$ & $\begin{array}{l}\text { Blood } \\
\text { loss } \\
\text { (mL) }\end{array}$ & $\begin{array}{c}\text { Hospital } \\
\text { stays } \\
\text { (days) }\end{array}$ & $\begin{array}{l}\text { Lymph } \\
\text { nodes }\end{array}$ & $\begin{array}{c}\text { Complication } \\
\text { (\%) }\end{array}$ & Survivals & $\begin{array}{c}\text { Reference } \\
\text { No. }\end{array}$ \\
\hline 2008 & Korea & 10 & Single & |A2-|B1 & 207 & 355 & 7.9 & 27.6 & 0.0 & NA & [7] \\
\hline 2008 & USA & 20 & Singe & IB1-IIA & 309 & 300 & 1 & 18 & 10.0 & $\begin{array}{c}\text { 2-year DFS } \\
90 \%\end{array}$ & [8] \\
\hline 2009 & Sweden & 80 & Single & |A1-||A & 262 & 150 & NA & 26 & 41.0 & NA & [9] \\
\hline 2009 & USA & 42 & Multi & |A1-|B2 & 215 & 50 & 1 & 25 & 16.8 & NA & [10] \\
\hline
\end{tabular}

NA, not available; DFS, disease-free survival. 


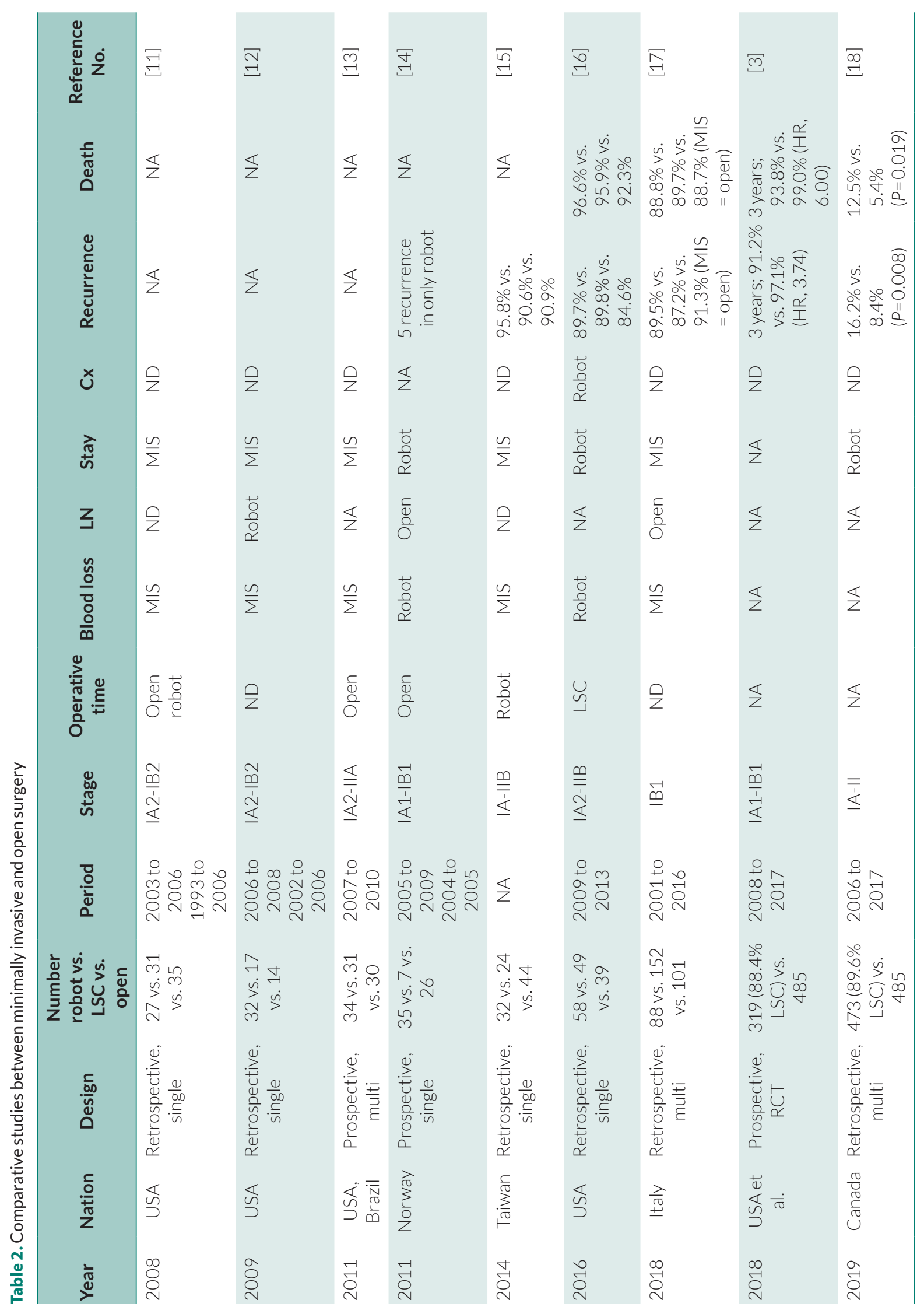




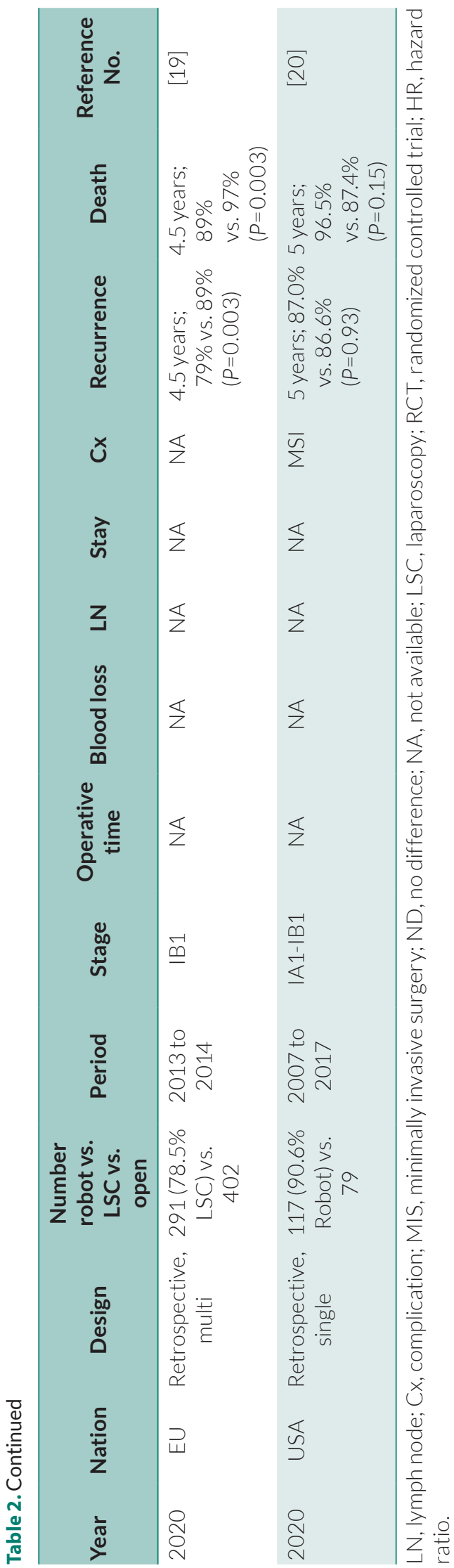

\section{ROBOT VS. OPEN SURGERY}

Most comparative studies showed that blood loss and hospital stays for the robot group were superior to those of the open group [21-31]. However, the majority of these studies demonstrated that the operative time of $\mathrm{ORH}$ was significantly shorter compared to RRH [21,23,26,28,29]. The survival outcomes of RRH and ORH were first reported in 2010, and for a 3-year progression free survival (PFS) were $94 \%$ in $\mathrm{RRH}$ and $89 \%$ in $\mathrm{ORH}(P=0.27)$ and the 3 -year OS were 94\% in RRH and 93\% in ORH ( $P=0.47)$, respectively [24]. After this study [24], several retrospective comparative studies showed that survival outcomes were similar between the two groups [28,29,31]. However, Wallin et al. [30] used a multivariate regression analysis and demonstrated that RRH was significantly more associated with tumor recurrence ( $\mathrm{HR}, 2.13$; $95 \% \mathrm{Cl}, 1.06-4.26$; $P<0.05)$. Moreover, abdominal radical hysterectomy had a greater PFS advantage over RRH for tumors $\geq 2 \mathrm{~cm}$ (HR, 0.31; 95\% Cl, 0.11-0.90; $P=0.04$ ) [32]. Furthermore, recent retrospective studies have also reported poor survival outcomes in RRH compared to ORH after propensity score matching (Table 3) [33,34].

\section{ROBOT VS. LAPAROSCOPY}

Surgical outcomes, such as the operative time and comlication rate were different for different studies [35-45]. However, most studies reported that blood loss of RRH was superior to that of LRH [35,37-39,45]. Finally, several retrospective studies have reported similar survival outcomes between the two groups (Table 4) [36-38,41,42,44,45].

\section{ROBOTIC SINGLE-SITE RH}

Sinno and Tanner [46] reported the first surgical film of robotic single-site RH. Recently, Jang et al. [47] compared the surgical outcomes of robotic single-site and multiport RH. Hospital stay and total hospital cost for single-site were significantly shorter and lower, respectively, compared to multiport surgery $(P<0.01)[47]$. 


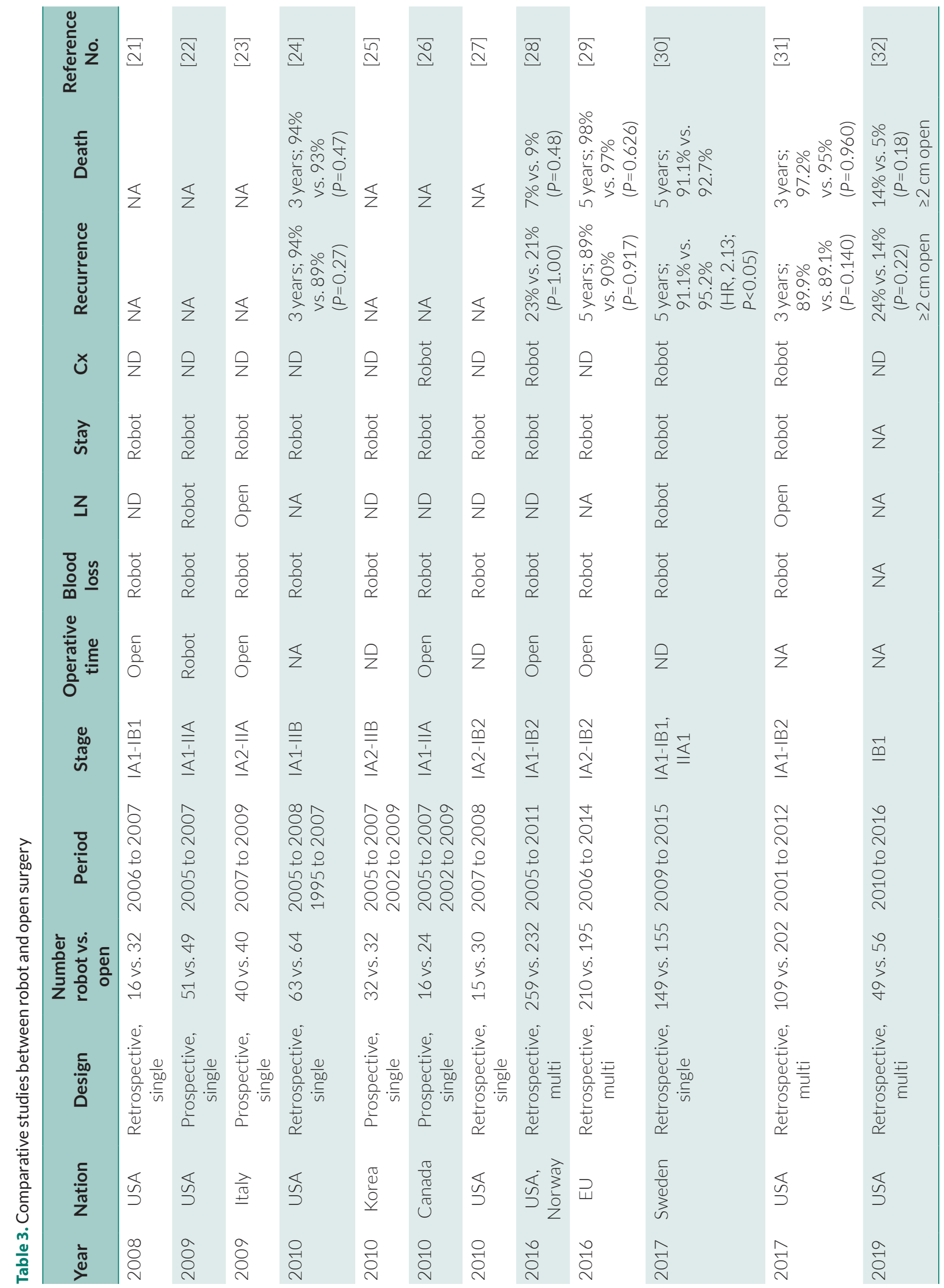




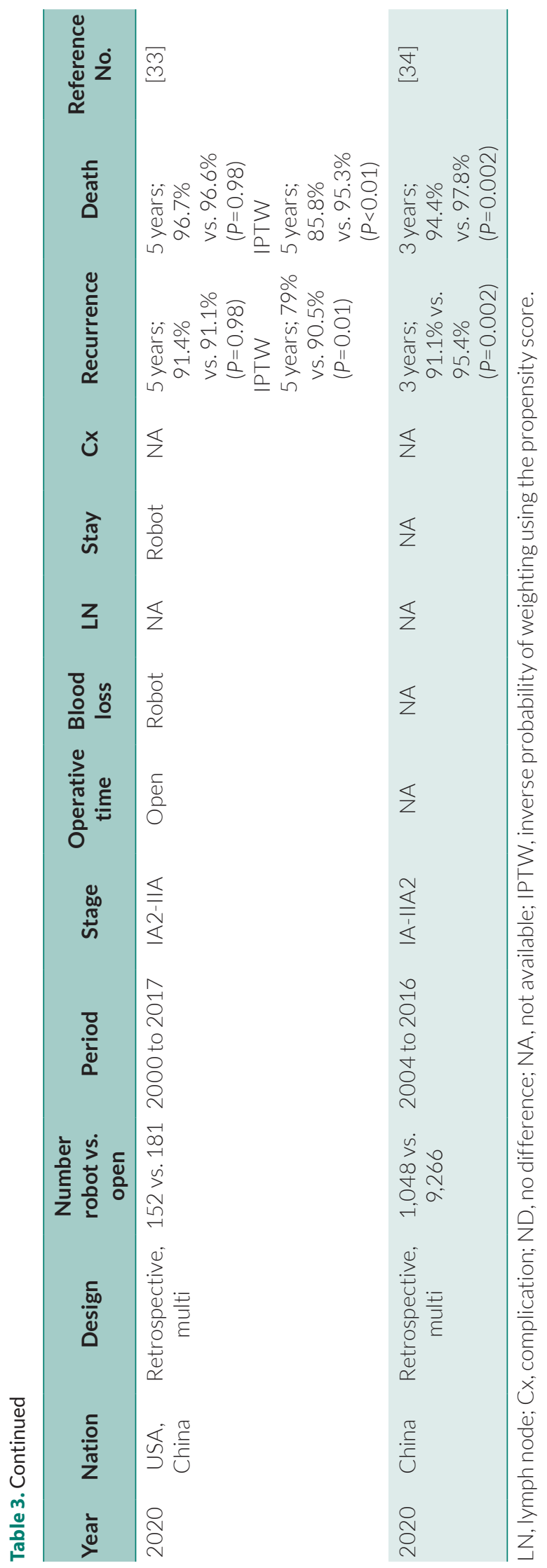

\section{NATIONWIDE POPULATION-BASED STUDIES}

In an epidemiologic study performed in the USA, MIS was associated with shorter OS rates compared to open surgery (HR, 1.65; 95\% Cl, 1.22-2.22; $P=0.002)$ [48]. In contrast, nationwide population-based studies in Scandinavia, reported different outcomes [49,50]. For instance, a Swedish nationwide population-based cohort study showed that the 5 -year OS was $94 \%$ and $92 \%$, and DFS was $88 \%$ and $84 \%$ for the robotic and open cohorts, respectively [49]. Moreover, the 5-year OS after propensity score matching was $92 \%$ for both cohorts (HR, 1.003; 95\% $\mathrm{Cl}, 0.5-2.01 ; P=0.99$ ) [49]. In a Danish nationwide population-based cohort study, adoption of RRH for early-stage cervical cancer was not associated with either an increased risk of recurrence or reduction in survival outcomes [50].

\section{ISSUES OF TUMOR SPILLAGE IN MIS}

In the LACC trials, the potential reasons for the inferior oncologic outcomes in the MIS included the routine use of uterine manipulator, effect of the insufflation gas $\left(\mathrm{CO}_{2}\right)$ on tumor-cell growth and that spread might increase the propensity for tumor spillage [3]. In the SUCCOR study, the use of uterine manipulator during MIS was associated with worse 4.5-year DFS (82\% vs. 93\%; HR, 3.48; 95\% Cl, 1.179.48, $P=0.028$ ) and 4.5-year OS (88\% vs. 96\%; $P=0.016)$ [19]. Klapdor et al. [51] evaluated peritoneal contamination with indocyanine green stained cervical secretion as surrogate for potential cervical cancer cell dissemination during colpotomy. Peritoneal contamination was detected in $75 \%$ (9/12) patients during laparoscopic hysterectomy and uterine manipulator contamination was detected in 60\% [51]. However, Nica et al. [52], reported that the use of intrauterine manipulator in patients with early cervical cancer who underwent MIS was not an independent factor with a significant rate of recurrence after controlling for adverse pathological factors ( $\mathrm{HR}, 0.4$; $95 \% \mathrm{Cl}, 0.2-1.0 ; P=0.05$ ). Kong et al. [53] demonstrated that the rate of disease recurrence was higher in the intracorporeal colpotomy group compared to the vaginal colpotomy group ( $16 \%$ vs. $5 \%$ ), and among patients with recurrence in the intracorporeal group, 62\% had intraperitoneal spread or carcinomatosis. 


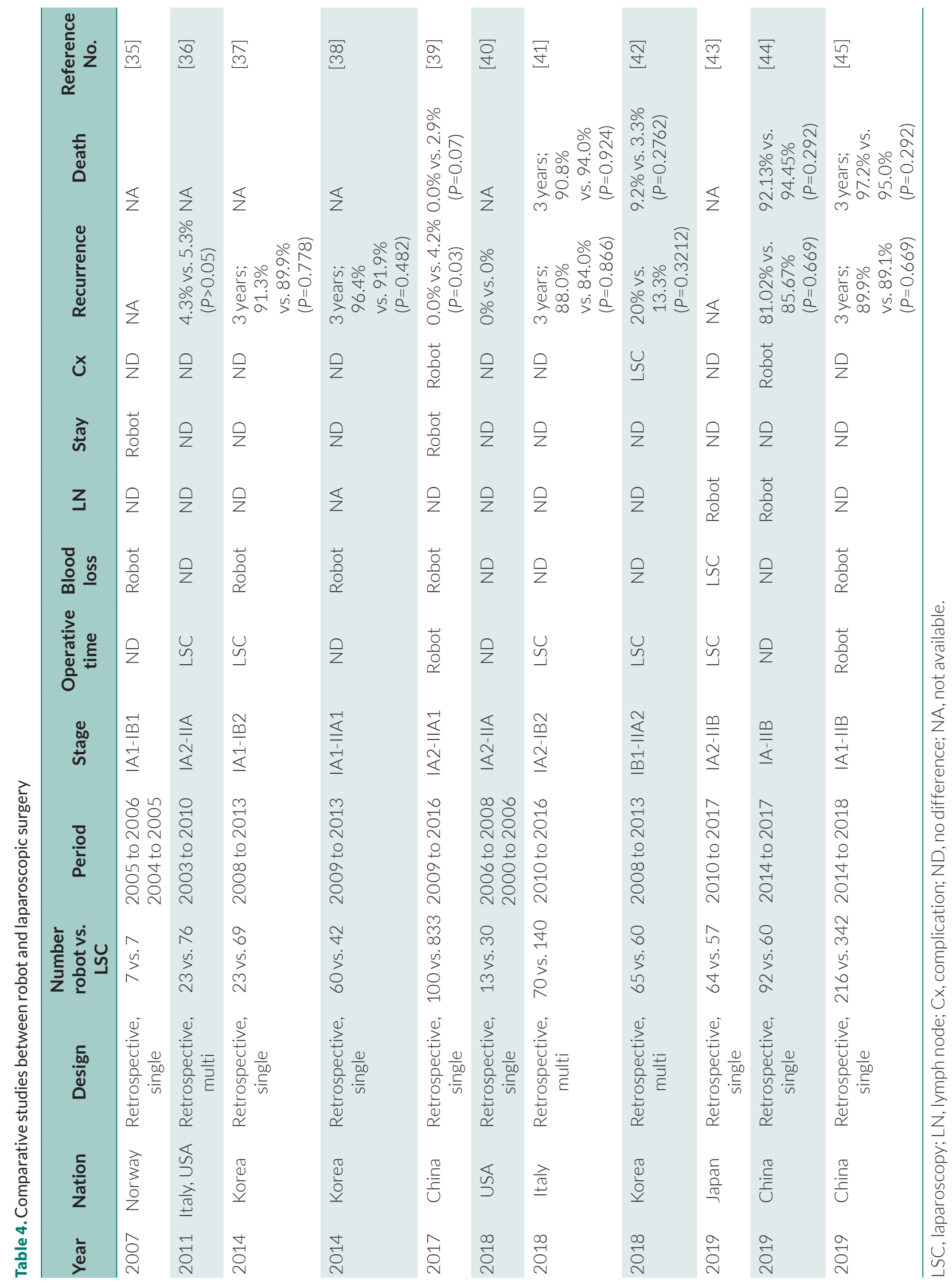


The author concluded that exposure of cervical cancer to circulating $\mathrm{CO}_{2}$ may result in tumor spillage into the peritoneal cavity [53]. Furthermore, other previous studies also presented intraperitoneal recurrences only in robot or MIS during $\mathrm{RH}[33,42]$.

\section{UPCOMING TRIALS}

Two novel noninferiority randomized controlled trials (RCTs) have been launched in terms of evaluating earlystage cervical cancer following the publication of the LACC trial results. The first one is a multicenter Chinese trial that compares RRH or LRH vs. ORH with DFS at 5 years as its primary objective, which has a planned sample size of 1,488 patients from 28 participating centers with an individual surgeon case volume [54]. The second one is performed in an international multicenter RCT (Robot-assisted Approach to Cervical Cancer [RACC] trial), and compares RRH vs. $\mathrm{ORH}$ with the 5-year DFS as its primary end-point and a planned sample size of 800 patients [55].

\section{CONCLUSION}

The authors of the LACC study and the US Cancer Resist Evaluation stated that MIS RH was associated with a higher rate of recurrence and poorer OS compared to ORH. Previous meta-analysis based on retrospective studies, showed that open surgery had no significant superiority.

The results were not interpreted as the end of MIS in terms of treating cervical cancer; instead, it was recommended that studies should be performed on how to avoid the use of uterine manipulators and the dissemination of cancer cells by ensuring a more effective vaginal closure using a standardized approach.

In agreement with previous nationwide population-based studies, our findings underline a disagreement on survival outcomes according to the specific conditions and parameters of each nation. Therefore, it is necessary to perform a Korean nationwide population-based study that will focus on the respective oncologic outcomes. Furthermore, strict guidelines for MIS in the treatment of early-stage cervical cancer should be implemented which will be consistent with objective data from the Korean population.

\section{Conflict of interest}

No potential conflict of interest relevant to this article was reported.

\section{References}

1. Frumovitz M, Ramirez PT, Greer M, Gregurich MA, Wolf J, Bodurka DC, et al. Laparoscopic training and practice in gynecologic oncology among Society of Gynecologic Oncologists members and fellows-in-training. Gynecol Oncol 2004;94:746-53.

2. Kim YB. Robotic surgery; into the era of common place. Gyne Robot Surg 2021;2:1-2.

3. Ramirez PT, Frumovitz M, Pareja R, Lopez A, Vieira M, Ribeiro R, et al. Minimally invasive versus abdominal radical hysterectomy for cervical cancer. N Engl J Med 2018;379:1895-904.

4. Society of Gynecologic Oncology (SGO). Notice to SGO members: emerging data on the surgical approach for radical hysterectomy in the treatment of women with cervical cancer [Internet]. New Orleans (LA): SGO; c2018 [cited 2020 Apr 1]. Available from: https://www.sgo.org/resources/notice-to-sgo-membersemerging-data-on-the-surgical-approach-for-radical-hysterectomy-in-the-treatment-of-women-with-cervical-cancer/.

5. National Comprehensive Cancer Network (NCCN). NCCN clinical practice guidelines in oncology: cervical cancer version 1 [Internet]. Plymouth Meeting (PA): NCCN; c2020 [cited 2020 Apr 1]. Available from: https://www.nccn.org/professionals/physician_gls/pdf/cervical_blocks.pdf.

6. Marchal F, Rauch P, Vandromme J, Laurent I, Lobontiu A, Ahcel B, et al. Telerobotic-assisted laparoscopic hysterectomy for benign and oncologic pathologies: initial clinical experience with 30 patients. Surg Endosc 2005;19:826-31.

7. Kim YT, Kim SW, Hyung WJ, Lee SJ, Nam EJ, Lee WJ. Robotic radical hysterectomy with pelvic lymphadenectomy for cervical carcinoma: a pilot study. Gynecol Oncol 2008;108:312-6.

8. Fanning J, Fenton B, Purohit M. Robotic radical hysterectomy. Am J Obstet Gynecol 2008;198:649.e1-4.

9. Persson J, Reynisson P, Borgfeldt C, Kannisto P, Lindahl B, Bossmar T. Robot assisted laparoscopic radical hysterectomy and pelvic lymphadenectomy with short and long term morbidity data. Gynecol Oncol 2009;113:185-90.

10. Lowe MP, Chamberlain DH, Kamelle SA, Johnson PR, Tillmanns TD. A multi-institutional experience with robotic-assisted radical hysterectomy for early stage cervical cancer. Gynecol Oncol 2009;113:191-4.

11. Magrina JF, Kho RM, Weaver AL, Montero RP, Magtibay PM. Robotic radical hysterectomy: comparison with laparoscopy and laparotomy. Gynecol Oncol 2008;109:86-91.

12. Estape R, Lambrou N, Diaz R, Estape E, Dunkin N, Rivera A. A case matched analysis of robotic radical hysterectomy with lymphad- 
enectomy compared with laparoscopy and laparotomy. Gynecol Oncol 2009;113:357-61.

13. Soliman PT, Frumovitz M, Sun CC, Dos Reis R, Schmeler KM, Nick AM, et al. Radical hysterectomy: a comparison of surgical approaches after adoption of robotic surgery in gynecologic oncology. Gynecol Oncol 2011;123:333-6.

14. Sert MB, Abeler $V$. Robot-assisted laparoscopic radical hysterectomy: comparison with total laparoscopic hysterectomy and abdominal radical hysterectomy; one surgeon's experience at the Norwegian Radium Hospital. Gynecol Oncol 2011;121:600-4.

15. Chen CH, Chiu LH, Chang CW, Yen YK, Huang YH, Liu WM. Comparing robotic surgery with conventional laparoscopy and laparotomy for cervical cancer management. Int J Gynecol Cancer 2014;24:1105-11.

16. Mendivil AA, Rettenmaier MA, Abaid LN, Brown JV 3rd, Micha JP, Lopez KL, et al. Survival rate comparisons amongst cervical cancer patients treated with an open, robotic-assisted or laparoscopic radical hysterectomy: a five year experience. Surg Oncol 2016;25:66-71.

17. Corrado G, Vizza E, Legge F, Pedone Anchora L, Sperduti I, Fagotti A, et al. Comparison of different surgical approaches for stage IB1 cervical cancer patients: a multi-institution study and a review of the literature. Int J Gynecol Cancer 2018;28:1020-8.

18. Cusimano MC, Baxter NN, Gien LT, Moineddin R, Liu N, Dossa $F$, et al. Impact of surgical approach on oncologic outcomes in women undergoing radical hysterectomy for cervical cancer. Am J Obstet Gynecol 2019;221:619.e1-619.e24.

19. Chiva L, Zanagnolo V, Querleu D, Martin-Calvo N, Arévalo-Serrano J, Căpîlna ME, et al. SUCCOR study: an international European cohort observational study comparing minimally invasive surgery versus open abdominal radical hysterectomy in patients with stage IB1 cervical cancer. Int J Gynecol Cancer 2020;30:1269-77.

20. Brandt B, Sioulas V, Basaran D, Kuhn T, LaVigne K, Gardner GJ, et al. Minimally invasive surgery versus laparotomy for radical hysterectomy in the management of early-stage cervical cancer: survival outcomes. Gynecol Oncol 2020;156:591-7.

21. Ko EM, Muto MG, Berkowitz RS, Feltmate CM. Robotic versus open radical hysterectomy: a comparative study at a single institution. Gynecol Oncol 2008;111:425-30.

22. Boggess JF, Gehrig PA, Cantrell L, Shafer A, Ridgway M, Skinner EN, et al. A case-control study of robot-assisted type III radical hysterectomy with pelvic lymph node dissection compared with open radical hysterectomy. Am J Obstet Gynecol 2008;199:357. e1-7.

23. Maggioni A, Minig L, Zanagnolo V, Peiretti M, Sanguineti F, Bocciolone L, et al. Robotic approach for cervical cancer: comparison with laparotomy: a case control study. Gynecol Oncol 2009;115:60-4.

24. Cantrell LA, Mendivil A, Gehrig PA, Boggess JF. Survival outcomes for women undergoing type III robotic radical hysterectomy for cervical cancer: a 3-year experience. Gynecol Oncol 2010;117:260-5.
25. Nam EJ, Kim SW, Kim S, Kim JH, Jung YW, Paek JH, et al. A case-control study of robotic radical hysterectomy and pelvic lymphadenectomy using 3 robotic arms compared with abdominal radical hysterectomy in cervical cancer. Int J Gynecol Cancer 2010;20:1284-9.

26. Halliday D, Lau S, Vaknin Z, Deland C, Levental M, McNamara E, et al. Robotic radical hysterectomy: comparison of outcomes and cost. J Robot Surg 2010;4:211-6.

27. Geisler JP, Orr CJ, Khurshid N, Phibbs G, Manahan KJ. Robotically assisted laparoscopic radical hysterectomy compared with open radical hysterectomy. Int J Gynecol Cancer 2010;20:438-42.

28. Sert BM, Boggess JF, Ahmad S, Jackson AL, Stavitzski NM, Dahl AA, et al. Robot-assisted versus open radical hysterectomy: a multi-institutional experience for early-stage cervical cancer. Eur J Surg Oncol 2016;42:513-22.

29. Zanagnolo V, Minig L, Rollo D, Tomaselli T, Aletti G, Bocciolone L, et al. Clinical and oncologic outcomes of robotic versus abdominal radical hysterectomy for women with cervical cancer: experience at a Referral Cancer Center. Int J Gynecol Cancer 2016;26:56874.

30. Wallin E, Flöter Rådestad A, Falconer H. Introduction of robotassisted radical hysterectomy for early stage cervical cancer: impact on complications, costs and oncologic outcome. Acta Obstet Gynecol Scand 2017;96:536-42.

31. Shah CA, Beck T, Liao JB, Giannakopoulos NV, Veljovich D, Paley P. Surgical and oncologic outcomes after robotic radical hysterectomy as compared to open radical hysterectomy in the treatment of early cervical cancer. J Gynecol Oncol 2017;28:e82.

32. Doo DW, Kirkland CT, Griswold LH, McGwin G, Huh WK, Leath CA 3rd, et al. Comparative outcomes between robotic and abdominal radical hysterectomy for IB1 cervical cancer: results from a single high volume institution. Gynecol Oncol 2019;153:242-7.

33. Yang J, Mead-Harvey C, Polen-De C, Magtibay P, Butler K, Cliby W, et al. Survival outcomes in patients with cervical cancer treated with open versus robotic radical hysterectomy: our surgical pathology interrogation. Gynecol Oncol 2020;159:373-80.

34. Chen B, Ji M, Li P, Liu P, Zou W, Zhao Z, et al. Comparison between robot-assisted radical hysterectomy and abdominal radical hysterectomy for cervical cancer: a multicentre retrospective study. Gynecol Oncol 2020;157:429-36.

35. Sert B, Abeler $\vee$. Robotic radical hysterectomy in early-stage cervical carcinoma patients, comparing results with total laparoscopic radical hysterectomy cases. The future is now? Int J Med Robot 2007;3:224-8.

36. Tinelli R, Malzoni M, Cosentino F, Perone C, Fusco A, Cicinelli E, et al. Robotics versus laparoscopic radical hysterectomy with lymphadenectomy in patients with early cervical cancer: a multicenter study. Ann Surg Oncol 2011;18:2622-8

37. Kim TH, Choi CH, Choi JK, Yoon A, Lee YY, Kim TJ, et al. Robotic versus laparoscopic radical hysterectomy in cervical cancer patients: a matched-case comparative study. Int J Gynecol Cancer 
2014;24:1466-73.

38. Yim GW, Kim SW, Nam EJ, Kim S, Kim HJ, Kim YT. Surgical outcomes of robotic radical hysterectomy using three robotic arms versus conventional multiport laparoscopy in patients with cervical cancer. Yonsei Med J 2014;55:1222-30.

39. Nie JC, Yan AQ, Liu XS. Robotic-assisted radical hysterectomy results in better surgical outcomes compared with the traditional laparoscopic radical hysterectomy for the treatment of cervical cancer. Int J Gynecol Cancer 2017;27:1990-9.

40. Nezhat FR, Datta MS, Liu C, Chuang L, Zakashansky K. Robotic radical hysterectomy versus total laparoscopic radical hysterectomy with pelvic lymphadenectomy for treatment of early cervical cancer. JSLS 2008;12:227-37.

41. Gallotta V, Conte C, Federico A, Vizzielli G, Gueli Alletti S, Tortorella L, et al. Robotic versus laparoscopic radical hysterectomy in early cervical cancer: a case matched control study. Eur J Surg Oncol 2018;44:754-9.

42. Chong GO, Lee YH, Lee HJ, Hong DG, Lee YS. Comparison of the long-term oncological outcomes between the initial learning period of robotic and the experienced period of laparoscopic radical hysterectomy for early-stage cervical cancer. Int J Gynecol Cancer 2018;28:226-32.

43. Oyama K, Kanno K, Kojima R, Shirane A, Yanai S, Ota Y, et al. Short-term outcomes of robotic-assisted versus conventional laparoscopic radical hysterectomy for early-stage cervical cancer: a single-center study. J Obstet Gynaecol Res 2019;45:405-11.

44. Han L, Yan P, Yao L, Liu R, Shao R, Liu J, et al. Safety and effectiveness of robotic hysterectomy versus conventional laparoscopic hysterectomy in patients with cervical cancer in China. Arch Gynecol Obstet 2019;300:153-60.

45. Chen L, Liu LP, Wen N, Qiao X, Meng YG. Comparative analysis of robotic vs laparoscopic radical hysterectomy for cervical cancer. World J Clin Cases 2019;7:3185-93.

46. Sinno AK, Tanner EJ 3rd. Robotic laparoendoscopic single site radical hysterectomy with sentinel lymph node mapping and pelvic lymphadenectomy for cervical cancer. Gynecol Oncol 2015;139:387.
47. Jang TK, Chung H, Kwon SH, Shin SJ, Cho CH. Robotic singlesite versus multiport radical hysterectomy in early stage cervical cancer: an analysis of 62 cases from a single institution. Int J Med Robot 2021;17:e2255.

48. Melamed A, Margul DJ, Chen L, Keating NL, Del Carmen MG, Yang J, et al. Survival after minimally invasive radical hysterectomy for early-stage cervical cancer. N Engl J Med 2018;379:1905-14.

49. Alfonzo E, Wallin E, Ekdahl L, Staf C, Rådestad AF, Reynisson P, et al. No survival difference between robotic and open radical hysterectomy for women with early-stage cervical cancer: results from a nationwide population-based cohort study. Eur J Cancer 2019;116:169-77.

50. Jensen PT, Schnack TH, Frøding LP, Bjørn SF, Lajer H, Markauskas $A$, et al. Survival after a nationwide adoption of robotic minimally invasive surgery for early-stage cervical cancer - a populationbased study. Eur J Cancer 2020;128:47-56.

51. Klapdor R, Hertel H, Hillemanns P, Röttger M, Soergel P, Kuehnle E, et al. Peritoneal contamination with ICG-stained cervical secretion as surrogate for potential cervical cancer tumor cell dissemination: a proof-of-principle study for laparoscopic hysterectomy. Acta Obstet Gynecol Scand 2019;98:1398-403.

52. Nica A, Kim SR, Gien LT, Covens A, Bernardini MQ, BouchardFortier $\mathrm{G}$, et al. Survival after minimally invasive surgery in early cervical cancer: is the intra-uterine manipulator to blame? Int J Gynecol Cancer 2020;30:1864-70.

53. Kong TW, Chang SJ, Piao X, Paek J, Lee Y, Lee EJ, et al. Patterns of recurrence and survival after abdominal versus laparoscopic/ robotic radical hysterectomy in patients with early cervical cancer. J Obstet Gynaecol Res 2016;42:77-86.

54. Chao X, Wu M, Ma S, Tan X, Zhong S, Song X, et al. Efficacy of different surgical approaches on survival outcomes in patients with early-stage cervical cancer: protocol for a multicentre longitudinal study in China. BMJ Open 2020;10:e038020.

55. Falconer H, Palsdottir K, Stalberg K, Dahm-Kähler P, Ottander U, Lundin ES, et al. Robot-assisted approach to cervical cancer (RACC): an international multi-center, open-label randomized controlled trial. Int J Gynecol Cancer 2019;29:1072-6. 